DOI: https://doi.org/10.38047/rct.v10i1.4416

\title{
O PASSADO DA HISTÓRIA: NOTAS SOBRE O DEBATE DA HISTÓRIA DA HISTORIOGRAFIA BRASILEIRA NA DÉCADA DE 1970
}

The past of history: Notes on the debate of the history of brazilian historiography in the 1970s.

\author{
Diego José Fernandes Freire*
}

Resumo: O presente trabalho visa apresentar o debate sobre a história da historiografia brasileira que houve nos anos 1970, adotando uma abordagem geral e panorâmica que prioriza a identificação dos autores, obras e instituições que marcaram tal discussão. Esboça-se ainda uma reflexão a respeito do significado e do sentido deste debate, no contexto setentista do último século.

Palavras-chave: Historiografia brasileira, Historiadores, Década de 1970

\begin{abstract}
The present paper aims to introduce the discussion on the history of Brazilian historiography that occurred in the 1970s, adopting a general approach that prioritizes the identification of the authors, works and institutions that marked such discussion. It is still outlined a reflection on the meaning and sense of this debate, in the context of the 70s of the last century.
\end{abstract}

Keywords: Brazilian historiography, Historians, The 1970's.

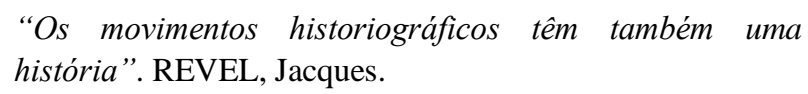

Atualmente, entre os historiadores, a discussão sobre a história da história, entendendo esta como uma disciplina histórica e socialmente situada, está em alta. Nas últimas décadas, em várias comunidades historiográficas, pode-se perceber um progressivo crescimento dos trabalhos em torno de uma história da historiografia. Fala-se entre os praticantes de Clio que nos dias correntes vive-se uma "Era epistemológica", isto é, um momento no qual a reflexão teórica sobre o fazer do historiador ganhou um impulso e uma consistência nunca vistos antes entre os historiadores. Como resultado desse crescimento, observa-se uma grande quantidade de trabalhos, fóruns, eventos, prêmios, linhas de pesquisa e revistas acadêmicas destinadas a uma investigação sobre a escrita da história, expressão que passou a fazer parte do vocabulário dos historiadores para indicar o próprio processo de produção e análise do conhecimento histórico.

\footnotetext{
* Licenciado e mestre em História pela Universidade Federal do Rio Grande do Norte. Doutorando no programa de Pósgraduação em História da Universidade Federal do Rio Grande do Sul. Professor da Secretaria de educação e cultura do Estado do Rio Grande do Norte.

${ }^{1}$ DELACROIX, Christian; DOSSE, François; GARCIA, Patrick. As corrente históricas na França: séculos XIX e XX. Tradução: Roberto Ferreira Leal. Rio de Janeiro: Editora FGV, 2012, p. 379.
} 
No Brasil, pode-se constatar essa pretendida "Era epistemológica" atentando-se para a existência de revistas como História da Historiografia, Teoria da história e Expedições: teoria da história e historiografia. À essas revistas, todas elas surgidas entre 2008-2010, somam-se também as linhas de alguns Programas de Pós-Graduação, as quais fomentam e viabilizam pesquisas em torno da elaboração do conhecimento histórico nas diferentes temporalidades. Nesse esboço cartográfico acerca das reflexões historiográficas atuais, pode-se acrescentar ainda o "Seminário Nacional de História da Historiografia", evento que desde 2007 vem formando um ambiente propício ao debate teórico e metodológico a respeito da história. Fruto de toda essa ambiência criou-se em 25 de agosto de 2009 um órgão institucional: a Sociedade Brasileira de Teoria e História da Historiografia. ${ }^{2}$

Como consequência de toda essa ambiência historiográfica, alguns autores chegaram a defender a existência de uma disciplina ou subdisciplina autônoma, voltada para investigações relacionadas à história da historiografia. Na França, destaca-se o nome de Charles-Olivier Carbonell, historiador que, desde sua tese de doutoramento de 1976, afirmou a importância de um olhar analítico em torno dos historiadores e de suas produções. Se em 1981 publica um pequeno livro contando a história da historiografia ocidental ${ }^{3}$, seu principal esforço, contudo, a respeito de um novo campo de estudos para os historiadores, foi realizado no ano seguinte, quando escreveu um artigo-manifesto, intitulado Pour une histoire de l'historiographie. Comentando este texto, Fernando Nicolazzi arremata: "o autor apontava para a necessidade de constituição de uma 'autêntica história da historiografia' ligada ao movimento mais abrangente de renovação do conjunto das ciências" ${ }^{4}$. Reivindicação semelhante, ainda que com justificativas e objetivos diferentes, foi também feita por Valdei Lopes de Araújo, aqui no Brasil, como evidencia o próprio título do artigo, Sobre o lugar da história da historiografia como disciplina autônoma, publicado em 2006, adotando uma postura afirmativa e já dada a respeito da especialidade intelectual em tela. ${ }^{5}$

Nestas páginas não cabe discutir se a história da historiografia é uma modalidade disciplinar autônoma ou não. Mostrar tal proposta já indicia o nível de efervescência intelectual que marca a época atual. Nesse sentido, focando no universo nacional, pode-se destacar também

\footnotetext{
${ }^{2}$ Para mais informações sobre este órgão, que visa "congregar os pesquisadores da área e de fortalecê-la no cenário intelectual nacional e internacional", ver: http://www.sbthh.ufop.br/ Acessado em 03 de março de 2018.

${ }^{3}$ CARBONELL, Charles-Olivier. Historiografia. Lisboa: Teorema, 1992.

${ }^{4}$ NICOLAZZI, Fernando. A história e seus passados: regimes historiográficos e escrita da história. In: BENTIVOGLIO, Julio; NASCIMENTO, Bruno César (Org.). Escrever história: historiadores e historiografia brasileira nos séculos XIX e XX. Serra: Editora Milfontes, 2017, p.10.

${ }^{5}$ ARAUJO, Valdei Lopes. Sobre o lugar da historiografia como disciplina autônoma. Locus, Juiz de Fora, V. 12, 2006, p. 79-94.
} 
as várias pesquisas sobre a história da historiografia brasileira, empreendidas, com grande intensidade, a partir dos anos 2000. A partir de Temistocles Cezar e Paulo Knauss, em um breve, mas significativo estudo sobre Manoel Luiz Salgado Guimarães ${ }^{6}$, pode-se sumariar que os recentes estudos historiográficos sobre a historiografia brasileira debruçam-se, prioritariamente, sobre os seguintes recortes temporais: segunda metade do século XIX, décadas iniciais do século XX (até 1930) e os anos 1980-1990. ${ }^{7}$

Sobre o recorte oitocentista, destacam-se trabalhos sobre o Instituto Histórico e Geográfico Brasileiro - IHGB (e suas variantes regionais), bem como acerca de letrados como Francisco Adolfo de Varnhagen, Silvio Romero e outros indivíduos relacionados à chamada geração de 1870. Sobre o século seguinte, avultam-se pesquisas em torno da geração ensaísta das primeiras décadas: Paulo Prado, Oliveira Viana, Gilberto Freyre, Sergio Buarque de Holanda, Caio Prado Junior etc. Aqui, também é comum trabalhos sobre a formação dos cursos de história em universidades como a de São Paulo e a do Distrito Federal, inauguradas em 1934 e 1935, respectivamente.

Por fim, fechando essa rápida e superficial cartografia disciplinar da atualidade a nível nacional, tem-se as investigações que problematizam a historiografia brasileira contemporânea, focando temas como a recepção de autores, temas e correntes historiográficas, a expansão da historiografia a partir da pós-graduação, debates epistemológicos e disputas políticas, entre outras temáticas. Como se vê, a área da história da historiografia, aqui lavrada por vários historiadores e historiadoras, cobre diversos momentos da própria história do Brasil, possuindo uma considerável variedade, senão de abordagens, certamente de objetos e assuntos. ${ }^{8}$

Por conta do predomínio desses recortes temporais, outros momentos da história da historiografia brasileira acabam recebendo pouca atenção, ficando a margem de muitas pesquisas acadêmicas. O presente trabalho visa justamente chamar a atenção para um outro momento desta história, apontando a existência de um amplo debate sobre a escrita da história do e no Brasil, realizado na década de 1970. Neste momento, a história, em sua face tropical, tornou-se um objeto de saber relevante para vários intelectuais das mais diferentes universidades do país, conforme se evidenciará nas próximas linhas. Parte-se do pressuposto de que a discussão sobre a história da historiografia brasileira, tão pungente nos dias que correm,

\footnotetext{
${ }^{6}$ CEZAR, Temistocles; KNAUSS, Paulo. O historiador e o viajante. In: GUIMARÃES, Manoel Luiz Salgado. Historiografia e nação no Brasil (1838-1857). Rio de Janeiro: EDUERJ, 2011, p.07-21.

${ }^{7}$ Chegou-se a esses recortes temporais a partir da nota de roda pé de número 22 do texto de Temistocles Cesar e Paulo Knauss, na qual os autores arrolam o que consideram os principais estudos de história da historiografia brasileira da atualidade.

${ }^{8}$ Para uma apreciação crítica em relação a esses estudos recentes, ver: GODOY, João Miguel Teixeira. Formas e problemas da historiografia brasileira. História Unisinos, vol 13, pp.66-77, 2009.
} 
possui uma historicidade na qual o recorte temporal do presente artigo ocupa um lugar importante, no sentido de consolidar temas, propostas e objetivos que até hoje marcam os estudos de historiografia.

Dessa forma, almeja-se apresentar a discussão sobre a história da historiografia brasileira ocorrida nos anos 1970, identificando autores, produções, espaços e algumas questões candentes na época. Oferecer uma cartografia disciplinar inicial, mapeando alguns elementos importantes, é a pretensão maior do corrente artigo. Nesse sentido, como questões estruturadoras, coloca-se: como ocorreu o debate sobre a história da historiografia brasileira nos anos 70 do século passado? Que temas surgiram? Quais foram os sujeitos que se envolveram nesse debate e a partir de quais produções intelectuais? O que estava em jogo no momento em que a historiografia nacional fortalecia-se como um objeto de saber? Eis algumas importantes questões a se colocar, não tanto para fornecer respostas prontas, mas sim para guiar a reflexão e clarear o caminho a ser percorrido.

O presente texto divide-se em três momentos, separados por tópicos específicos. No primeiro, que marca uma aproximação inicial com o debate setentista relativo ao passado da historiografia brasileira, explicita-se os principais autores e suas produções. Em seguida, partese para um grupo social mais específico da discussão, sempre com a abordagem cartográfica de mapear autores e obras. Por fim, procura-se discutir o significado, em termos de história da historiografia, de toda a discussão sobre a produção histórica nacional no contexto dos anos 1970. Mais do que rechaçar as produções setentistas sobre a historiografia brasileira, colocandoas como ultrapassadas, reducionistas e superadas, adjetivos que pouco acrescentam em termos de conhecimento, mas que estabelecem identitariamente um "Outro" e um "Nós", um "Antes" e um "Depois", busca-se inventaria-las, explicitando suas linhas gerais, seus traços mais significativos e seus principais representantes.

\section{A HISTORIOGRAFIA BRASILEIRA EM QUESTÃO}

O gesto teórico de pensar acerca da historicidade da história, refletindo sobre seus métodos, procedimentos e vinculações sociais, não surgiu efetivamente na atualidade. $\mathrm{Na}$ Europa, encontram-se registro de discussões teóricas e historiográficas desde o século XIX. Como exemplo, na historiografia alemã, tem-se As grandes linhas da história (1837), de Georg Gottfried Gervinus, e $O$ estado da moderna historiografia alemã (1856), escrito por Heinrich Von Sybel. Na França, também no mesmo século, encontram-se livros como As diferentes 
maneiras de se escrever a história (1884) e Estudos históricos na França (1889), publicados, respectivamente, por Augusto Thierry e Gabriel Monod. ${ }^{9}$

E no Brasil, quando se iniciou reflexão semelhante, tomando a historiografia em sua historicidade como objeto de estudo?

Segundo Rebeca Gontijo, excetuando o necrológio de Varnhagen escrito em 1878 por Capistrano de Abreu, data do início do século XX os primeiros textos que ousaram refletir sobre a historiografia brasileira. Segue a lista apresentada por aquela historiadora: Os historiadores do Brasil no século XIX, de Alcides Bezerra, publicado em 1926; dois artigos franceses, Aperçu de la production historique recent au Brésil, de Émile Coornaert, publicado em 1936, e Notes et refléxions sur le travail historique au Brésil, de Henri Hauser, de 1937; e ainda, O pensamento histórico no Brasil nos últimos 50 anos, de Sergio Buarque de Holanda, publicado no jornal Correio da Manhã, em 1951. ${ }^{10}$

Na verdade, pode-se apontar que, até a década de 1970, existiram pontuais iniciativas no que tange a uma reflexão sobre a história produzida aqui no Brasil. Nesse sentido, deve-se sublinhar a figura de José Honório Rodrigues (1913-1987), erudito que, formado em Direito, mas apaixonado pela história, dedicou inúmeros livros e artigos para discutir textos históricos. Observando títulos como Teoria da história do Brasil (1949), A pesquisa histórica no Brasil (1952), História e historiadores do Brasil (1965), História e historiografia (1970), História da história do Brasil (1979) fica a impressão que José Honório Rodrigues foi o primeiro autor nacional a produzir sistematicamente análises teóricas e historiográficas sobre a nossa produção histórica $^{11}$. Em meados dos anos de 1970, entretanto, ele ganhou a companhia - concorrência? - de outros intelectuais.

Seguindo a vereda desbravada por José Honório Rodrigues, vários indivíduos formados em universidades - instituição existente no país desde 1934 - passaram a realizar investigações historiográficas. Seis anos após o Golpe civil-militar, historiadores de ofício (em geral), e não mais diletantes eruditos, resolveram tomar a historiografia brasileira como objeto de estudo. Colocando uma lupa na musa Clio em sua face tupiniquim, inúmeros autores, vários textos e diferentes iniciativas foram elaboradas. Nesse sentido, observam-se a produção e a atuação de autores como Francisco Iglesias (1923-1999), José Roberto do Amaral Lapa (1929-2000) e Nilo

\footnotetext{
${ }^{9}$ MARTINS, Estevão de Rezende (org.). A história pensada: teoria e método na historiografia europeia do século XIX. São Paulo: Contexto, 2010, p. 09.

${ }^{10}$ GONTIJO, Rebeca. A história da historiografia, 1940-1970: apontamentos sobre sua escrita. In: XXVI Simpósio Nacional de História da ANPUH. Anais do XXVI Simpósio Nacional de História da ANPUH. São Paulo: ANPUH, 2011, p. 02.

${ }^{11}$ FREIXO, André de Lemos. A arquitetura do novo: ciência e história da História do Brasil em José Honório Rodrigues [Tese de Doutorado em História]. Rio de Janeiro: UFRJ, 2012.
} 
Odália (1929-2004), professores universitários que, em forte dialogo na região sudeste do país, teceram várias reflexões sobre o passado de sua área disciplinar. Assim, algumas palavras sobre esse trio se fazem necessárias.

Aluno da primeira turma do curso de história da Universidade de Minais Gerais ${ }^{12}$, Francisco Iglesias graduou-se em 1944, tendo atuando, sobretudo, na área de história econômica e política, a partir de seu lugar institucional na Faculdade de Ciências Econômicas daquela instituição de ensino. Porém, em várias produções, o historiador mineiro dedicou-se a pensar a historicidade nacional de seu saber, como indica alguns artigos do livro, publicado em 1971, História e Ideologia, bem como os vários artigos que escreveu ao longo dos anos 1970 e o seu projeto de uma "história da história nacional", idealizado nos anos 1980, mas que acabou não se concretizando. Tal projeto, inacabado, foi publicado em 2000, postumamente, como livro, denominado sintomaticamente de Historiadores do Brasil: capítulos de historiografia brasileira.

Duas produções dão bem o tom do lugar privilegiado que Francisco Iglesias ocupou enquanto historiador da historiografia brasileira: em 1979, participa do projeto de Mário Guimarães e Shozo Motoyoma, de fornecer um amplo quadro da história das ciências no Brasil, escrevendo o capítulo sobre a disciplina histórica; em 1983, realiza para o Conselho Nacional de Desenvolvimento Científico e Tecnológico (CNPQ) a avaliação do campo historiográfico brasileiro "a luz de sua história". Por conta dessa preocupação com a historicidade da história no e do Brasil, Alessandra Soares Santos defende que "a reflexão sobre a historiografia e, especialmente, sobre a história da historiografia brasileira esteve sempre presente no percurso intelectual de Francisco Iglésias. Ele é justamente considerado, ao lado de José Honório Rodrigues, um dos precursores dos estudos do gênero no Brasil”. ${ }^{13}$

José Roberto do Amaral Lapa, além de historiador, também era formado em Ciências Jurídicas e Sociais (1959), pela Pontifícia Universidade Católica de Campinas. Sua formação em história, concluída nesta mesma universidade em 1952, ocorreu no momento em que o ensino superior de história estava conjunto com a Geografia. Assim como Francisco Iglesias, nos anos 1970 apresentou um vívido interesse pela historiografia brasileira, em especial por sua

\footnotetext{
12 Tal instituição representa a origem da atual Universidade Federal de Minas Gerais. No momento em que Francisco Iglésias fez sua formação em história, tal curso estava vinculado ao de geografia, união que permaneceu até 1957. Sobre a formação de Francisco Iglésias, bem como sobre sua escrita da história, conferir o excelente trabalho de: SANTOS, Alessandra Soares. A universidade, a história e o historiador: o itinerário intelectual de Francisco Iglésias (1940-1990). Tese de doutorado apresentada ao programa de pós-graduação em História da Universidade Federal de Minas Gerais, 2013, 350p.

${ }^{13}$ SANTOS, Alessandra Soares. A universidade, a história e o historiador: o itinerário intelectual de Francisco Iglésias (1940-1990). Tese de doutorado apresentada ao programa de pós-graduação em História da Universidade Federal de Minas Gerais, 2013, p. 261.
} 
história, materializado, principalmente, no livro A história em questão: historiografia brasileira contemporânea, publicado em 1976. Nesta produção, seu autor conjuga o passado e o presente da historiografia nacional, sem perder também de vista o próprio futuro da produção histórica, a partir de um exame que intenta fornecer uma radiografia precisa do objeto em foco, diagnosticando sua historicidade, suas agruras e suas tendências. Com essa proposta em mente, e definindo historiografia como análise crítica do conhecimento histórico, José Roberto do Amaral Lapa analisa o IHGB, os intérpretes do Brasil e os cursos universitários de história de sua época. ${ }^{14}$

Na década de 1970, José Roberto do Amaral Lapa teve um importante interlocutor, com quem partilhou seus interesses historiográficos:

Quanto aos trabalhos de historiografia brasileira aguardo-os com interesse, gostaria mesmo, caso isso lhe seja possível, de vê-los até antes de publicados, pois me jogaram um curso de Historiografia Brasileira em nosso mestrado em História, o que está me obrigando a transformar o que era um simples flerte em namoro, que talvez até acabe dando em casamento. Até o mês que vem deverá sair alguma coisa que resultou das minhas reflexões nesse terreno. Mandarei a você, pois me interessam as suas críticas. ${ }^{15}$

O destinatário da carta, datada de 17 de 1976, é Nilo Odália, filósofo de formação pela Universidade de São Paulo (USP) em 1955, mas com um forte transito entre os historiadores, a partir de sua atuação no museu paulista e na Faculdade de Filosofia, Ciências e Letras de Assis e Araraquara, tendo, na primeira, participado da estruturação do curso de história e atuado como docente nas disciplinas de "Introdução aos estudos históricos" e "Teoria da História". No que diz respeito a história da historiografia brasileira, assim se pronunciou Nilo Odália, relembrando os anos de 1970:

Eu tinha um plano, um projeto que eu não pude realizar em Assis, com muita dor no coração, que era fazer uma História da historiografia brasileira com meus alunos de pós-graduação, se nós chegássemos a ter pós-graduação. Eu falei: "Bom, se eu quero fazer isso, eu tenho que começar pelo pai. Então, falei: quem é o pai? O pai é Varnhagen." Então, essa missão é minha porque eu vou fazê-la servir como um exemplo do que deve ser feito pelos demais. ${ }^{16}$

Fruto deste seu projeto, veio sua tese de livre-docência, escrita entre 1975-1978 e defendida no ano de 1979 em Araraquara, intitulada As formas do mesmo: um estudo de

\footnotetext{
${ }^{14}$ LAPA, José Roberto do Amaral. A história em questão: historiografia brasileira contemporânea. Petrópolis: Vozes, 1976.

${ }^{15}$ ANHEZINE, Karina. Arautos da história da historiografia: as disputas por um conceito de historiografia nas cartas de Amaral Lapa e Nilo Odália. Revista Patrimônio e Memória. São Paulo, Unesp, Vol. 11, Num. 41, p. 421, janeiro-junho, 2015, p. 10.

${ }^{16}$ CORREAA, Anna Maria Martinez; DIAS, Márcia Regina Tosta. Entrevista com o professor Nilo Odália, Cadernos CEDEM, São Paulo, v. 2, n. 1, p. 83-97, 2011, p. 95. Disponível em: <http://www2.marilia.unesp.br/revistas/index.php/cedem/article/view/689>. Acesso em 15 de abril de 2018.
} 
historiografia ${ }^{17}$. A despeito da insistência de Amaral Lapa para a publicação da tese, o trabalho só virou livro em 1997, embora fosse bem conhecido entre os historiadores do eixo Rio-São Paulo logo após a defesa. Em 1979, somando mais uma produção sobre a história da historiografia brasileira, Nilo Odália organizou na Editora Ática uma coleção sobre Varnhagen.

Francisco Iglesias, José Roberto do Amaral Lapa e Nilo Odália, ao lado de José Honório Rodrigues, animaram o debate sobre a historiografia brasileira na segunda metade do século passado. Suas produções balizaram várias discussões nos mais variados cursos de história espalhados pelo Brasil, bem como em importantes congressos científicos. É interessante apontar que entre esses autores existiu um forte dialogo, de modo que um rápido cruzamento de suas produções evidenciará a existência de uma forte intertextualidade. Assim, nos idos de 1970 a discussão sobre a historiografia nacional não era realizada por um único autor, mas por vários intelectuais, em sua maioria docentes em universidades do sudeste do país. Dai porque, como chama atenção Karina Anhezini, o próprio conceito de historiografia não apresentava na época um consenso estável ${ }^{18}$. A variedade de posições ilustra bem o grau e a situação plural do debate.

Alguns autores, como Amaral Lapa, defendiam um entendimento que fizesse os estudos de historiografia se aproximarem da história econômica e social de base quantitativista, ao passo que Nilo Odália via seu projeto como a possibilidade de uma real aproximação entre história e filosofia. Ampliando a discórdia - e para ficarmos apenas nos autores citados neste parágrafo , Francisco Iglesias advogava um conceito preciso e recortado de historiografia, que o distinguisse de documentos normalmente confundidos como obra histórica: crônicas, manuscritos, tratados, anais, entre outros ${ }^{19}$. Na verdade, além do conceito de historiografia, muitos outros elementos estavam em jogo.

Se há uma discordância salutar quanto ao conceito de historiografia, os três autores, porém, procuram vincular suas reflexões à história do Brasil. Primeiro, no sentido de relacionar história e historiografia, não encarando esta produção como algo solto no ar, etéreo, sem sofrer os constrangimentos sociais, políticos e culturais de época. Em alguns momentos, tal relação é até exagerada, descampando para determinismos nos quais a obra é mero reflexo da realidade. Em seguida, operam com a noção de historiografia enquanto escrita da história no e do Brasil.

\footnotetext{
${ }^{17}$ ODÁLIA, Nilo. As formas do mesmo: ensaios sobre o pensamento historiográfico de Varnhagen e Oliveira Viana. São Paulo: Editora da UNESP, 1997.

${ }^{18}$ ANHEZINE, Karina. Arautos da história da historiografia: as disputas por um conceito de historiografia nas cartas de Amaral Lapa e Nilo Odália. Revista Patrimônio e Memória São Paulo, Unesp, Vol. 11, Num. 41, p. 421, janeiro-junho, 2015, p.15

${ }^{19}$ IGLÉSIAS, Francisco. Comentário ao texto de Alice Piffer Canabrava. In: Anais do I Seminário de Estudos Brasileiros. São Paulo: IEB/USP, 1971, Vol. II, p. 23.
} 
Tal fato é bastante importante na economia discursiva dos textos de Francisco Iglesias, José Roberto do Amaral Lapa e Nilo Odália.

Segundo os autores de Brazilian historical writing in global perspective ${ }^{20}$, a noção de historiografia entre os historiadores brasileiros, durante boa parte do século XX, carregou consigo uma forte dose de ambiguidade, sendo, inclusive, bastante polissêmica. Termos como estudos históricos, pensamento histórico, conhecimento histórico e obras históricas, até os anos 1980 eram usados como sinônimo de historiografia. Desse modo, nem sempre este termo indicou história-disciplina, para o quê também contribuiu o caráter recente dos cursos de história nas universidades brasileiras. Daí porque muitos historiadores, em especial dos anos 1970, mas atualmente também, utilizam o termo historiografia para o século XIX, a despeito de nesta época inexistir a história-disciplina na sociedade brasileira, entendendo disciplina como um conjunto de saberes praticados e ensinados a partir de regras próprias (no caso da história, o método histórico dos historiadores oitocentistas da Alemanha e França) em um local institucional acessível a todos.

É justamente essa polissemia do termo historiografia que permite a Francisco Iglesias, José Roberto do Amaral Lapa e Nilo Odália a pensarem tanto como conhecimento no Brasil, como área de saber praticada por vários indivíduos, formados em um curso superior de história ou não, quanto como conhecimento sobre o Brasil. É nessa duplicidade semântica que seus livros operam, o que permite a eles unir historiografia e história do Brasil. Com isso, tais autores conseguem refletir a respeito da história-disciplina na sociedade brasileira e também acerca da historiografia relativa ao Brasil, não deixando, assim, de pensar em termos nacionais. Em forma de pergunta, pode-se apontar que as seguintes questões ecoavam: como a história foi praticada no Brasil? Sendo praticada, que conhecimento histórico (ou historiografia) foi produzido sobre a nação brasileira? As duas questões são importantes, inseparáveis até, e é nelas que se pensa quando se usa a expressão história da historiografia brasileira.

Não se pode perder de vista o fato de que intelectuais universitários como Francisco Iglesias, José Roberto do Amaral Lapa e Nilo Odália, assim como vários outros, vivenciaram uma época na qual os Estados Nacionais, a despeito da Globalização que no momento já mostrava sua força, tinha uma importância essencial, pautando várias discussões e outros tantos projetos de mudanças. Era a época da Guerra Fria, da bipolaridade entre dois regimes socioeconômicos que se confundia com dois países: Estado Unidos da América x União das

\footnotetext{
${ }^{20}$ PEREIRA, Mateus H. de F.; SANTOS, Pedro A. C. dos; NICODEMO, Thiago L. Brazilian historical writing in global perspective: on the emergence of the concept of "historiography". History and Theory, Theme Issue 54, december, 2015, p.84-104.
} 
Repúblicas Socialistas Soviéticas. Socialismo e Capitalismo apontavam também para realidades nacionais, exemplificadas nos dois países citados, de modo que discutir tais regimes era ter em mente Estados Nacionais específicos. ${ }^{21}$

No caso brasileiro em particular, havia toda a atmosfera do nacionaldesenvolvimentismo da ditadura civil-militar, que colocava a nação tanto no presente, no sentido de diagnosticar e proteger a realidade nacional, quanto no futuro, com o objetivo de se criar um novo país, desenvolvido e soberano. Pensar a nação brasileira era uma realidade irresistível e incontornável para a intelectualidade nacional da segunda metade do século $\mathrm{XX}^{22}$. Enfatize-se que pensar a nação não era apenas um gesto intelectual ou um simples tema de pesquisa acadêmica, como era também uma atitude fundamentalmente política, que indicava uma preocupação nacional imiscuída com um forte desejo de mudança, de transformação do país. O que é o Brasil? O que o Brasil vai ser? Que projeto nacional deve-se defender? Questões urgentes na época para boa parte da intelectualidade brasileira, em que ciência, política e nação constituíam termos quase que indissociáveis. Sensível a essa conjuntura, a história da historiografia brasileira, tal qual feita pelos intelectuais universitários era também uma oportunidade para se pensar a nação, tanto quanto o próprio conhecimento histórico, ainda que em um contexto nacional preciso.

A história do e no Brasil estava na mira dos historiadores setentistas, de forma praticamente indissociável, de modo que não se pensava em uma sem se pensar na outra. Uma conduzia a outra, dentro do debate setentista sobre a história da historiografia brasileira. Historicizando a historiografia brasileira, tinha-se a oportunidade de contemplar, em perspectiva temporal, um duplo fenômeno: a escrita da história no Brasil e sobre o Brasil. A historiografia era pensada como uma prática científica, como um conhecimento específico, a história, mas uma prática científica voltada para um objeto preciso, o Brasil, a nação. A categoria historiografia brasileira carregava tanto uma marca epistemológica quanto identitária. Com essa junção, refletir sobre a história era igualmente pensar sobre o país na qual a historiografia tinha lugar. Na feliz expressão de Jacques Rancière, havia uma "política do saber", que transformava o pensamento sobre uma disciplina em uma visada sobre a própria

\footnotetext{
${ }^{21}$ HOBSBAWM, Eric. Era dos extremos: o breve século XX (1914-1991). São Paulo: Companhia das Letras, 1995, p.234.

${ }^{22}$ WASSERMAN, Claudia. Identidade nacional: o Brasil para seus intelectuais. Revista Acervos, Vol.19., Num. 1-2., jan/dez, 2006, p. 31-32.
} 
ação ${ }^{23}$. Daí se discutir, dentro de uma proposta de história da historiografia brasileira, a história no e do Brasil.

\title{
OS HISTORIADORES USPIANOS
}

\author{
"O discurso acadêmico nesse instante desdobra-se e se \\ questiona". DECCA, Edgar de.
}

Dentro do grupo de intelectuais universitários que participaram do debate setentista sobre a historiografia brasileira, pode-se recortar um grupo específico, o qual será abordado neste tópico: os historiadores uspianos. Chama-se de historiadores uspianos os indivíduos que tiveram o seu processo formativo profissional ligado a Universidade de São Paulo (USP), sendo construído e construindo-se com um certo ethos historiográfico. Na base desta definição, está a relação entre indivíduo e instituição formadora, pensada a partir da seguinte visão, tal qual exposta por Pierre Bourdieu: "os homens formados em uma dada disciplina ou em uma determinada escola, partilham um certo ‘espírito’, literário ou científico. Tendo sido moldados segundo o mesmo 'modelo', os espíritos assim modelados encontram-se predispostos a manter com seus pares uma relação de cumplicidade e comunicação imediatas". ${ }^{24}$ Profissionais como Maria de Lourdes Mônaco Janotti, Raquel Glezer, Maria Odila Leite da Silva Dias ${ }^{25}$ e Carlos Guilherme Mota, entre outros que realizaram sua graduação e pós-graduação em uma única e mesma universidade, adquiriram certas características comuns, em razão de partilharem um mesmo background intelectual, dado pelas leituras, orientações ${ }^{26}$, valores e conflitos que vivenciaram em um espaço institucional específico.

Apontar isso não significa dizer que entre os historiadores uspianos não se teria nenhuma diferença substantiva. Longe disso, pois é notório que cada indivíduo subjetiva sua identidade profissional a partir de variáveis não só históricas, como também particulares. O que se pretende assinalar é a existência de traços profissionais relativamente comuns, no que diz respeito às formas de pensar, praticar e defender a história enquanto área disciplinar ${ }^{27}$. Afinal, o métier do historiador é uma atividade aprendida, e todo aprendizado, realizado em uma dada

\footnotetext{
${ }^{23}$ RANCIÈRE, Jacque. Políticas da escrita. Rio de Janeiro: Editora 34, 1995, p.210.

${ }^{24}$ BOURDIEU, Pierre. Economia das trocas simbólicas. São Paulo: Perspectiva, 1973, p. 206.

${ }^{25}$ Como se vê, a presença feminina nesse grupo se destaca, abrindo a possibilidade de uma discussão de gênero, o que, em razão das escolhas metodológicas do presente artigo, não será aqui feito.

${ }^{26}$ Nesse quesito, o nome de Eduardo de Oliveira França destaca-se, tendo, dos trabalhos aqui citados, orientando os de Maria de Lourdes Janotti, Pedro Alcântara Figueira e Jayro Gonçalves Melo. Sobre tal nome, ver: ROIZ, Diogo da Siva; FARIAS, Marcilene Nascimento de. Eduardo de Oliveira França e a escrita da história das civilizações. Revista Emblemas, V.8., N.2., Jul.-Dez., 2011.

${ }^{27}$ Perspectiva semelhante foi adotada por Lidiane Soares Rodrigues, ao estudar os intelectuais uspianos que participaram do famoso grupo $O$ Capital. Ver: RODRIGUES, Lidiane Soares. A produção social do marxismo universitário em São Paulo: mestres, discípulos e 'um seminário'. Tese de doutorado apresentada ao programa de pós-graduação em História Social da Universidade de São Paulo, 2011.
} 
instituição, deixa marcas consideráveis no aprendiz, as quais estruturam seu ofício. Se a história é um fazer, como apontam vários autores na atualidade, se os historiadores passam por L'Atelier de l'histoire, como colocou certa vez François Furet, não é de todo inadequado apontar uma relativa semelhança entre aqueles e aquelas que passaram por uma oficina historiográfica específica.

Falar em historiadores uspianos também não implica em concordar com a afamada proposta da existência de uma "escola histórica uspiana", como acreditam alguns autores ${ }^{28}$. Esta expressão conceitual exagera os elementos identitários, realizando uma uniformização inadequada de um conjunto de historiadores deveras plural e ambíguo. Além do mais, ele supõe também uma harmonização entre os profissionais, uma concórdia entre os pares provenientes da mesma instituição, apagando, assim, as disputas e as tensões inerentes a toda e qualquer comunidade intelectual. Desse modo, o recorte aqui sugerido, não pretende reforçar nenhuma identidade homogênea de grupo, tratando-se apenas de um procedimento heurístico para melhor clarificar os sujeitos envolvidos no debate setentista sobre a historiografia nacional.

No contexto em apreço, a produção histórica nacional universitária encontrava maior vitalidade no Departamento de História (DHIS) da USP. Segundo Carlos Fico e Ronald Polito, dos 309 trabalhos de pós-graduação em história defendidos no Brasil entre 1973-1979, os historiadores uspianos compareceram com 132 trabalhos, perfazendo 41,3\% do total ${ }^{29}$. Com essa média de trabalhos, o DHIS da USP concentrou em termos numéricos não só a produção historiográfica, mas também uma efervescente reflexão em torno da história da historiografia brasileira.

Em 1971, realizou-se na Universidade de São Paulo (USP) o I seminário de Estudos Brasileiros, o qual contou com uma mesa redonda acerca dos "Estudos Históricos no Brasil"; neste mesmo ano, Maria de Lourdes Janotti defendeu sua tese na USP denominada João Francisco Lisboa: historiador e jornalista. No ano seguinte, Maria Odila Leite da Silva Dias concluiu também na USP sua tese intitulada Robert Shouthey, historiador do Brasil. Em 1973, Pedro Alcântara Figueira defendeu na Faculdade de Filosofia, Ciência e Letras de Assis - SP a tese Historiografia Brasileira: análise crítica (1900-1930), orientado pelo catedrático uspiano

\footnotetext{
${ }^{28} \mathrm{Se}$ os historiadores uspianos comprometidos com uma escrita da história da historiografia brasileira viam-se como um grupo unido, como uma escola, é uma questão a se investigar, que demanda um esforço para além deste artigo. Nesse momento, registramos apenas a construção identitária a posteriori: CAPELATO, Maria Helena R.; GLEZER, Raquel.; FERLINI, Vera Lúcia Amaral. Escola Uspiana de História. Estudos avançados. Ano 8., Num.22., 1994, 349-358.

${ }^{29}$ FICO, Carlos; POLITO, Ronald. A história no Brasil (1980-1989): elementos para uma análise. Ouro Preto: Editora da UFOP, 1992, Vol. 1., p.42
} 
Eduardo de Oliveira França. No ano de 1975, ocorreu a tese de livre docência de Carlos Guilherme Mota, Ideologia da cultura brasileira ${ }^{30}$, saudada por inúmeros historiadores e cientistas sociais da época como um clássico das Ciências Humanas brasileira. Chegando em 1977, dois importantes trabalhos são defendidos na USP: a tese de Jayro Gonçalves Melo, sobre Capistrano de Abreu, e o trabalho de Raquel Glezer, acerca de um dos nomes mais expressivo do debate historiográfico no Brasil, José Honório Rodrigues. Este último trabalho, tentando inclusive pensar e propor um novo modelo de análise da historiografia brasileira, a partir de um estudo de caso específico, indica de forma contundente como a preocupação relativa a história da historiografia brasileira estava em ebulição entre os historiadores uspianos. ${ }^{31}$

Os trabalhos destacados sumariamente no parágrafo anterior revelam pontos importantes no que toca ao debate alvo destas páginas. Os historiadores uspianos, ao contrário dos seus pares universitários que também refletiam sobre a historiografia brasileira, apresentados no tópico anterior, adotaram objetos de pesquisa claramente delimitados. Se Francisco Iglesias, José Roberto do Amaral Lapa e Nilo Odália vão enunciar no titulo de seus trabalhos o termo historiografia brasileira, não especificando logo de saída um objeto mais circunscrito, a produção dos uspianos vai na direção oposta, recortando o universo de investigação: Robert Southey (1774-1843), João Francisco de Lisboa (1812-1863), Capistrano de Abreu (1853-1927) e José Honório Rodrigues (1913-1987), como se fosse estudos de caso. O enfoque holista parece ser bem menor aqui, em detrimento do objeto recortado, o que sugere uma operação teórico-metodológica do grupo uspiano. ${ }^{32}$

Além disso, tais objetos de pesquisa - ou estudos de caso - apresentam um arco temporal que vai do final do século XVIII, passando por todo o Oitocentos, até chegar a primeira metade do século XX. Se a viagem é uma dimensão estruturante da figura do historiador, seja no mundo antigo ou no moderno, como destacou François Hartog, esse "deslocamento no tempo" 33 das pesquisas dos historiadores uspianos precisa ser sublinhado, ainda que de passagem. A investigação de objetos em diferentes épocas, uns mais distantes e outros mais próximos ao

\footnotetext{
28 Apesar de não explicitar no título referência a história da historiografia, esta abordagem é perceptível no trabalho, já que seu autor elegeu como objeto privilegiado a produção histórica dos letrados do começo do século XX, recorte esse que encaminha para uma nítida revisão da historiografia brasileira. Nesse sentido, ver a introdução e a parte inicial da seguinte obra: MOTA, Carlos Guilherme. Ideologia da cultura brasileira. Rio de Janeiro: Editora 34, 2011.

${ }^{31}$ GLEZER, Raquel. O fazer e o saber na obra de José Honório Rodrigues: um modelo de análise historiográfica. Tese de doutorado defendida na Universidade de São Paulo, 1977, 2 Vols.

32 Assim como o elemento de gênero destacado na nota 25 , chama-se a atenção para a possibilidade de relacionar história da historiografia brasileira e biografia, procedimento já feito por vários trabalhos, ainda que para outro recorte temporal.

${ }^{33}$ HARTOG, François. Os antigos, o passado e o presente. Brasília: Editora da UNB, 2003., p.12
} 
presente dos uspianos, serve bem para indicar o quanto a questão da historiografia brasileira inquietava esses intelectuais universitários. O objeto de saber em foco, a história do e no Brasil, era tratado na duração, na processualidade do tempo, inclusive do tempo mais próximo. História da historiografia brasileira, expressão comum nos anos 1970, fazia todo sentido. Deslocandose no tempo, objetiva-se flagrar a historiografia nacional em diferentes épocas, vendo-a, assim, em termos históricos, quase que na longa duração.

Somando-se às teses e aos eventos, no âmbito do DHIS da USP, tem-se também a atuação do primeiro periódico universitário de história, a Revista de História, cujo primeiro número veio à baila em $1950^{34}$. Tal periódico, durante a década de 1970, acolheu várias publicações sobre a historiografia brasileira, tanto em sua faceta pretérita como também contemporânea, constituindo-se como um local importante deste debate. Para ficarmos em um exemplo, aponte-se que o seu número 88, do terceiro trimestre de 1971, apresentou ao público acadêmico nacional uma edição praticamente voltada para a historiografia brasileira, com vários artigos sobre esta temática ${ }^{35}$. A partir de uma gama de iniciativas, um pensar a história no e do Brasil adquiriu nítidos contornos no DHIS da USP, tendo, inclusive, um certo ar de urgência. Longe de ser um assunto de um único autor, a reflexão sobre a história da historiografia brasileira foi um tema coletivo, também no interior de uma das principais universidades do país.

Interessante pontuar que, embora a discussão sobre a historiografia brasileira tenha ganhado corpo na USP na década de 1970, existem pontuais registros anteriores desta reflexão. É o caso, por exemplo, de dois textos. O primeiro, de 1951, escrito por Astrogildo Rodrigues de Melo, professor da cadeira de História da Civilização Americana, e denominado Os estudos históricos no Brasil, em que se historiciza a história do e no Brasil desde a época colonial até a época presente do artigo. Destaque especial é concedido ao DHIS da USP, encarado como um "laboratório de pesquisa"36. O segundo texto, de 1961 e intitulado de Esboço da historiografia brasileira nos séculos XIX e XX, é da autoria de Pedro Moacyr Campos, professor-adjunto da cadeira de História da Civilização Antiga e Medieval. Aqui, seu autor fez um exaustivo balanço

\footnotetext{
${ }^{34}$ ALVES, Fabrício Gomes. Folheando páginas, descobrindo histórias: a Revista de História e a difusão da historiografia dos Annales no Brasil (1950-1960). Dissertação apresentada ao programa de pós graduação em história da Universidade Federal da Paraíba, 2010.

${ }^{35}$ Revista de história. São Paulo: Universidade de São Paulo, Num. 88, 1971.

${ }^{36}$ MELO, Astrogildo Rodrigues de. Os estudos históricos no Brasil. Revista de história. São Paulo, Vol.02, Num. 06, p. 01-10, 1951, p.10.
} 
da historiografia brasileira nos séculos XIX e XX, passando em revista autores e obras que foram fundamentais para o pensamento histórico nacional. ${ }^{37}$

Assim como o artigo de Astrogildo Rodrigues de Melo, a ideia de contribuição é essencial no texto de Pedro Moacyr Campos, atuando como um elemento não só organizador da narrativa, como também hierarquizador do material historiográfico em apreço. Tal proposta, sem dúvida, pavimenta o caminho para a discussão sobre os méritos da criação do curso de história da USP, encarado como um verdadeiro marco na história da historiografia brasileira. Aliás, entre os historiadores uspianos, será um topos comum a discussão sobre o papel da Faculdade de Filosofia, Letras e Ciências Humanas ${ }^{38}$ no desenvolvimento da historiografia brasileira. Não raro, assim como o curso de história do DHIS da USP, tal centro também é elevado com distinção ao patamar de marco da historiografia brasileira, já que, além dos historiadores uspianos, abrigou também intelectuais como Fernando de Azevedo, João Cruz Costa, Florestan Fernandes, Antônio Candido, os quais escreveram obras de história, dando assim contribuições ao pensamento histórico, portanto a historiografia brasileira.

Cumpre ainda dizer que Esboço da historiografia brasileira nos séculos XIX e XX, embora tenha surgido inicialmente na Revista de História do DHIS da USP, foi produzido para compor um dos capítulos do livro Iniciação aos estudos históricos, publicado em 1961 e escrito por Jean Glénisson, historiador francês que foi um dos responsáveis pela cátedra de Metodologia e Teoria da história ${ }^{39}$, entre 1957-1958 ${ }^{40}$. Tal fato mostra a relevância do texto de Pedro Moacyr Campos dentro da comunidade historiográfica uspiana, alçado à condição de texto introdutório e incontornável ao estudante brasileiro que desejava se iniciar nos estudos históricos.

\footnotetext{
${ }^{37}$ CAMPOS, Pedro Moacyr. Esboço da historiografia brasileira nos séculos XIX e XX. In: GLÉNISSON, Jean. Iniciação aos estudos históricos. São Paulo: DIFEL, 1961.

${ }^{38}$ Antiga Faculdade de Filosofia, Ciências e Letras (FFCL). A mudança de nomenclatura ocorre na transição dos anos 1960 para os 1970, mais precisamente e oficialmente em 1969, com a criação da cidade universitária no Butantã. Ver: http://www5.usp.br/institucional/a-usp/historia/linha-do-tempo/ Acessado em 15 de abril de 2018.

${ }^{39}$ Boa parte dos intelectuais universitários que se envolveram na reflexão sobre a historiografia brasileira, durante os anos 1970, ministrava na época disciplinas como introdução aos estudos históricos, metodologia da história e teoria da história, componentes curriculares que, a partir de fins dos anos 1950, foram progressivamente ocupando o currículo dos cursos de história do país. Sobre a relação entre essas disciplinas e a reflexão em torno da história da historiografia, ver: WEHLING, Arno. Historiografia e epistemologia histórica. In: MALERBA, Jurandir (org.). A história escrita: teoria e história da historiografia. São Paulo: Contexto, 2006.

${ }^{40}$ ROIZ, Diogo da Silva. Os caminhos (da escrita) da história e os descaminhos de seu ensino: a institucionalização do ensino universitário de História na Faculdade de Filosofia, Ciências e Letras da Universidade de São Paulo (1934-1968). Curitiba: Appris, 2012, p. 43.
} 
Dessa forma, entre os historiadores uspianos $^{41}$, a discussão sobre o passado da historiografia brasileira não começou efetivamente nos anos 1970. Apontar tal constatação é importante não só para historicizar o debate alvo destas páginas, mas, principalmente, para dimensionar o seu papel e o seu sentido enquanto tema coletivo e sistemático de uma comunidade disciplinar específica. Nesse sentido, o depoimento de Fernando Novais, comparando sua época de graduação (segunda metade dos anos 1950) com a historiografia pós implementação do sistema de pós-graduação atual (1971), é salutar: “eu tenho a impressão, e acho que a maior parte dos meus colegas de geração também, que nós despertamos para o interesse de historiografia com essa mudança na historiografia brasileira. Nos primeiros tempos, nós não estávamos preocupados com isso" ${ }^{42}$. A partir dessa virada historiográfica, emergiu um movimento historiográfico que colocou a história nacional em questão, tornando-a um tópico de reflexão e pesquisa para vários historiadores e historiadoras.

Além dos eventos passados, dos acontecimentos pretéritos, das estruturas políticas, sociais e econômicas que sustentam realidades antigas, tradicionalmente estudadas pelos historiadores, passou-se a interrogar também a própria disciplina histórica, a produção nacional dos historiadores. O gesto de voltar-se para si, em termos disciplinares, como sugere a epígrafe inicial deste tópico, trazendo palavras de alguém que não só vivenciou os anos de 1970 mas que também externou uma autoconsciência historiográfica, foi algo evidente. Não à toa, o trabalho de Edgar de Decca, fechando a década, estabeleceu um crítico dialogo com a historiografia brasileira, a partir da tradicional temática da Revolução de $1930^{43}$, procedimento também feito por Boris Fausto em seu A Revolução de 1930: historiografia e história, porém no final dos anos de $1960 .{ }^{44}$

Como explicar esse despertar historiográfico ocorrido em uma comunidade disciplinar? Eis aí uma questão que ainda não recebeu a devida e merecida atenção.

\section{HISTÓRIA E HISTORIOGRAFIA}

Valdei Lopes de Araújo, em um claro desdobramento das interrogações de Michel de Certeau, questionou certa vez: "o que está em jogo quando fazemos história da

\footnotetext{
${ }^{41}$ Nem no universo intelectual brasileiro se começou a discutir tal temática nos anos 1970 . No início do primeiro tópico, com alguns textos e, principalmente, com a obra de José Honório Rodrigues, sublinhou-se tal fato.

${ }^{42}$ NOVAIS, Fernando. Francisco Iglésias e a historiografia. In: PAULA, João Antônio de (Org.). Presença de Francisco Iglésias. Belo Horizonte: Autêntica, 2001, p. 58.

${ }^{43}$ DECCA, Edgar de. O silencio dos vencidos. São Paulo: Brasiliense, 1981, p.13.

${ }^{44}$ FAUSTO, Boris. A Revolução de 1930: historiografia e história. São Paulo: Brasiliense, 1970.
} 
historiografia?"45 Esboçando uma tentativa de resposta a esta questão crucial, pode-se propor a ideia segundo a qual os historiadores adentraram no debate setentista sobre a história do seu campo disciplinar para erigirem novos modelos de explicação, contrapondo-se aos que estavam até então estabelecidos, isto é, os trabalhos de José Honório Rodrigues, autor ainda filiado a uma tradição ensaística e enciclopédica de história da historiografia. Nesse sentido, as palavras de Maria de Lourdes Mônaco Janotti, em sua tese de doutorado, parecem valer por todo um grupo de historiadores, traduzindo e sintetizando sensações, inquietações e projetos de quem estava refletindo sobre sua disciplina:

A historiografia brasileira tem sido insuficientemente estudada. A pobreza do
número e do conteúdo de obras que se ocupam de tal matéria revela um campo
ainda inexplorado, que aguarda investigação metódica. Ela tem sido tratada
por dois tipos de obras: as histórias da literatura e os estudos isolados sobre
historiadores. Estes tipos de trabalho se caracterizam por uma completa
assistematização processual. [...] A validade dos estudos historiográficos
supõe um julgamento da obra de historia, não como simples trabalho de
inspiração individual, mais ou menos bem sucedida, mas compreendida como
o resultado material e intelectual de uma determinada sociedade com
problemas econômico-sociais, políticos e ideológicos bem definidos. [...]
Deve-se aspirar a uma história da historiografia com problemas
historiográficos. ${ }^{46}$

A urgência de renovação é latente, como se as obras anteriores, a despeito de serem feitas desde 1949, data do livro Teoria da história do Brasil de José Honório Rodrigues, não tivessem tratado adequadamente da matéria. Dessa ausência, surgiriam os vários trabalhos em torno da história da historiografia brasileira. Esta área disciplinar, apesar dos estudos, estaria carente de passado, missão para a qual, a partir de então, se dedicariam vários historiadores. Tal missão implicaria tanto em rejeitar os modelos anteriores como em elaborar novos modelos de análise, com base em uma gramática efetivamente científica, proveniente da historiografia universitária. Daí as críticas aos estudos passados e o apelo de renovação historiográfica, procedimentos também endossados por Fernando Novais: “os estudos historiográficos são e devem ser feitos por historiadores, levando em conta uma problemática teórica da historiografia" ${ }^{47}$. O movimento interno de fechamento sobre si, como que blindando de prováveis "intrusos", não poderia ser mais claro: a historiografia universitária brasileira, a partir de sua formação e de suas demandas teórico-metodológicas, deveria se assenhorear das discussões em torno da historiografia brasileira.

\footnotetext{
${ }^{45}$ ARAUJO, Valdei Lopes. Sobre o lugar da historiografia como disciplina autônoma. Locus, Juiz de Fora, V. 12, 2006, p.02.

${ }^{46}$ JANOTTI, Maria de Lourdes. João Francisco Lisboa: historiador e jornalista. Tese apresentada a Universidade de São Paulo, 1971, p.10.

${ }^{47}$ NOVAIS, Fernando. Francisco Iglésias e a historiografia. In: PAULA, João Antônio de (Org.). Presença de Francisco Iglésias. Belo Horizonte: Autêntica, 2001, p.58.
} 
A queixa de que os estudos de historiografia não estavam sendo devidamente realizados é um ponto em comum entre todos os trabalhos da década de 1970, para além dos historiadores uspianos. Muitos trabalhos, inclusive, anunciam sua motivação vindo dessa incompletude e fragilidade. Mais do que preencher lacunas, contudo, pode-se analisar tal reclame como sendo parte das disputas do campo intelectual historiográfico. Em relação aos professores universitários, José Honório Rodrigues representava um outsider, já que, formado em Ciências Jurídicas, não estava ligado a nenhuma instituição de ensino superior. Como a historiografia, área de saber que desde os anos 1930 era ensinada e pesquisada em universidades brasileiras, poderia continuar sendo matéria privilegiada de um bacharel em direito à moda antiga? ${ }^{48}$ Era necessário disputar, tensionar tal temática, missão para a qual vários historiadores e professores universitários se lançaram entusiasticamente.

Outra disputa intelectual importante consiste no afastamento do modelo da história da literatura brasileira, baseada na sucessão de autores, obras e escolas literárias de forma linear e cronológica. Esse combate se justifica porque em fins do século XIX e início do XX era muito frequente historicizar a literatura nacional e, junto com essa historicização, inserir as obras históricas. Autores como Silvio Romero e Ronald de Carvalho, em suas histórias da literatura brasileira, realizaram tal procedimento ${ }^{49}$. O próprio José Honório Rodrigues, no seu afã de catalogar as obras históricas desde o período colonial, algumas vezes reproduziu o modelo de história da literatura, produzindo mais uma listagem enciclopédica de autores e obras do que propriamente uma análise histórica da historiografia. Tal é a avaliação de Carlos Guilherme Mota. ${ }^{50}$

Se as histórias da literatura inseriam a produção histórica no campo das artes, os historiadores setentistas do século XX, rejeitando tal abordagem, darão ênfase especial no caráter social da historiografia, adotando, conforme já colocado, análises um tanto quanto deterministas, com base na noção de ideologia ou praticando uma sociologia do conhecimento. O repertório marxista, ligado a autores como Karl Mannheim e Lucien Goldman, mobilizado por vários intelectuais universitários no debate, auxilia na tarefa de pensar e demonstrar a

\footnotetext{
${ }^{48}$ Para aumentar ainda mais esse provável incomodo, cabe destacar que, durante os anos de 1960 e 1970, os textos de José Honório Rodrigues eram muito usados nos curso de história, nas áreas de introdução, metodologia e teoria da história. Nesse sentido, conferir algumas das entrevistas contidas no seguinte livro: MORAES, José Geraldo Vinci de \& REGO, José Marcio (Entrevistadores). Conversas com historiadores brasileiros. São Paulo: Ed. 34, 2002.

${ }^{49}$ CEZAR, Temistocles. O poeta e o historiador. Southey e Varnhagen e a experiência historiográfica no Brasil do século XIX. História Unisinos, v. 11, p. 306-312, 2007.

${ }^{50}$ MOTA, Carlos Guilherme. A historiografia brasileira nos últimos quarenta anos: tentativa de avaliação crítica. Revista Debate \& Crítica. Num. 05., p. 1-26, 1975, p.02.
} 
dimensão contextual da historiografia. Daí porque, como aponta Maria de Lourdes Mônaco Janotti, "o estudo das condições ambientais em que vive o historiador é tão importante quanto as citações bibliográficas contidas em sua obra. E estas bem podem ser o produto daquelas" ${ }^{\text {" }}$. Reforçar a dimensão histórica da historiografia não era, assim, uma simples postura de metodologia científica, mero ato desinteressado. Antes, tinha a ver com as disputas intelectuais travadas dentro e fora do campo historiográfico.

Não se pode também ignorar o fato de que a reflexão sobre a historiografia brasileira, seja em sua dimensão pretérita ou presente, era encarada como parte importante dos esforços de profissionalização e consolidação do campo da história na sociedade brasileira. Historicamente, o conhecimento historiográfico, tanto da disciplina histórica quanto das produções dos historiadores, foi reivindicado como elemento marcante de uma disciplina que se propõe social e academicamente científica. Daí porque a reflexão historiográfica é contemporânea do próprio processo de cientifização da história. Não há história sem métodos tanto quanto não há história sem uma reflexão sobre esses métodos, no passado e no presente.

Essa relação entre historiografia e afirmação da história como ciência, no sentido forte e distintivo do termo ciência, aparece claramente no livro-manual de Jean Glénisson, Iniciação aos estudos históricos, obra produzida para coroar a missão francesa na FFCL da USP e guiar os próximos passos da historiografia brasileira rumo a cientificidade, longe de todo amadorismo e do antiquariato. Vale lembrar que a produção ora em apreço, além de apresentar os aspectos teórico-metodológicos da história, tal qual os mestres metódicos do século XIX, Langlois e Seignobos, historiciza também a própria disciplina, em sua feição pretensamente universal (de Heródoto até Braudel) e brasileira, com o texto de Pedro Moacyr Campos já indicado. Como ressalta Julio Arostegui, teoria, metodologia e (história da) historiografia constituem tripés essenciais da moderna ciência da história, tanto na tradição historicista alemã como na positivista francesa. ${ }^{52}$

Desse modo, entende-se o tom e o modo de urgência com que os historiadores na década de 1970 se lançaram a uma reflexão sobre a história da historiografia brasileira. Quando se faz história da historiografia, muita coisa está em jogo, a depender da época, dos indivíduos envolvidos e do próprio contexto institucional de produção. Os historiadores objetos deste

\footnotetext{
${ }^{51}$ JANOTTI, Maria de Lourdes. João Francisco Lisboa: historiador e jornalista. Tese apresentada a Universidade de São Paulo, 1971, p.10.

${ }^{52}$ AROSTEGUI, Julio. A pesquisa histórica. Bauru: EDUSC, 2006, p.43.
} 
artigo manifestaram claramente uma consciência acerca da relevância do que faziam, tanto em termos intelectuais como sócio-políticos. Afinal, era a sua historiografia que estava em jogo. Portanto, não se tratava apenas de um objeto de pesquisa, nem muito menos de um título a se conseguir, ou de um simples trabalho acadêmico a se concluir a fim de galgar postos profissionais na universidade. Era a própria disciplina que estava em jogo, o seu passado, presente e futuro.

Recebido em: 20/04/2018

Aceito em: 17/05/2018

\section{REFERÊNCIAS BIBLIOGRÁFICAS}

ALVES, Fabrício Gomes. Folheando páginas, descobrindo histórias: a Revista de História e a difusão da historiografia dos Annales no Brasil (1950-1960). Dissertação apresentada ao programa de pós-graduação em história da Universidade Federal da Paraíba, 2010, 210p.

ANHEZINE, Karina. Arautos da história da historiografia: as disputas por um conceito de historiografia nas cartas de Amaral Lapa e Nilo Odália. Revista Patrimônio e Memória São Paulo, Unesp, Vol. 11, Num. 41, p. 4-21, janeiro-junho, 2015.

ARAUJO, Valdei Lopes. Sobre o lugar da historiografia como disciplina autônoma. Locus, Juiz de Fora, V. 12, 2006, p. 79-94.

AROSTEGUI, Julio. A pesquisa histórica. Bauru: EDUSC, 2006.

BOURDIEU, Pierre. Economia das trocas simbólicas. São Paulo: Perspectiva, 1973.

CAMPOS, Pedro Moacyr. Esboço da historiografia brasileira nos séculos XIX e XX. In: GLÉNISSON, Jean. Iniciação aos estudos históricos. São Paulo: DIFEL, 1961.

CAPELATO, Maria Helena R.; GLEZER, Raquel.; FERLINI, Vera Lúcia Amaral. Escola Uspiana de História. Estudos avançados. Ano 8., Num.22., 1994, 349-358.

CARBONELL, Charles-Olivier. Historiografia. Lisboa: Teorema, 1992.

CEZAR, Temistocles. O poeta e o historiador. Southey e Varnhagen e a experiência historiográfica no Brasil do século XIX. História Unisinos, v. 11, p. 306-312, 2007.

CEZAR, Temistocles; KNAUSS, Paulo. O historiador e o viajante. In: GUIMARÃES, Manoel Luiz Salgado. Historiografia e nação no Brasil (1838-1857). Rio de Janeiro: EDUERJ, 2011.

CORRÊA, Anna Maria Martinez; DIAS, Márcia Regina Tosta. Entrevista com o professor Nilo Odália, Cadernos CEDEM, São Paulo, v. 2, n. 1, p. 83-97, 2011. Disponível em: <http://www2.marilia.unesp.br/revistas/index.php/cedem/article/view/689>. Acesso em $15 \mathrm{de}$ abril de 2018.

DECCA, Edgar de. 1930: O silencio dos vencidos. São Paulo: Brasiliense, 1981.

DELACROIX, Christian; DOSSE, François; GARCIA, Patrick. As correntes históricas na França: séculos XIX e XX. Tradução: Roberto Ferreira Leal. Rio de Janeiro: Editora FGV, 2012. 
FAUSTO, Boris. A Revolução de 1930: historiografia e história. São Paulo: Brasiliense, 1970. FICO, Carlos; POLITO, Ronald. A história no Brasil (1980-1989): elementos para uma análise. Ouro Preto: Editora da UFOP, 1992, Vol. 1.

FREIXO, André de Lemos. A arquitetura do novo: ciência e história da História do Brasil em José Honório Rodrigues [Tese de Doutorado em História]. Rio de Janeiro: UFRJ, 2012.

GLEZER, Raquel. O fazer e o saber na obra de José Honório Rodrigues: um modelo de análise historiográfica. Tese de doutorado defendida na Universidade de São Paulo, 1977, 2 Vols.

GONTIJO, Rebeca. A história da historiografia, 1940-1970: apontamentos sobre sua escrita. In: XXVI Simpósio Nacional de História da ANPUH. Anais do XXVI Simpósio Nacional de História da ANPUH. São Paulo: ANPUH, 2011.

HARTOG, François. Os antigos, o passado e o presente. Brasília: Editora da UNB, 2003.

HOBSBAWM, Eric. Era dos extremos: o breve século XX (1914-1991). São Paulo: Companhia das Letras, 1995.

IGLÉSIAS, Francisco. Comentário ao texto de Alice Piffer Canabrava. In: Anais do I Seminário de Estudos Brasileiros. São Paulo: IEB/USP, 1971, Vol.II, p. 22-34.

JANOTTI, Maria de Lourdes. João Francisco Lisboa: historiador e jornalista. Tese apresentada a Universidade de São Paulo, 1971.

LAPA, José Roberto do Amaral. A história em questão: historiografia brasileira contemporânea. Petrópolis: Vozes, 1976.

MARTINS, Estevão de Rezende (org.). A história pensada: teoria e método na historiografia europeia do século XIX. São Paulo: Contexto, 2010.

MELO, Astrogildo Rodrigues de. Os estudos históricos no Brasil. Revista de história. São Paulo, Vol.02, Num. 06, p. 01-10, 1951.

MORAES, José Geraldo Vinci de \& REGO, José Marcio (Entrevistadores). Conversas com historiadores brasileiros. São Paulo: Ed. 34, 2002.

MOTA, Carlos Guilherme. A historiografia brasileira nos últimos quarenta anos: tentativa de avaliação crítica. Revista Debate \& Crítica. Num. 05., p. 1-26, 1975.

MOTA, Carlos Guilherme. Ideologia da cultura brasileira. Rio de Janeiro: Editora 34, 2011.

NICOLAZZI, Fernando. A história e seus passados: regimes historiográficos e escrita da história. In: BENTIVOGLIO, Julio; NASCIMENTO, Bruno César (Org.). Escrever história: historiadores e historiografia brasileira nos séculos XIX e XX. Serra: Editora Milfontes, 2017.

NOVAIS, Fernando. Francisco Iglésias e a historiografia. In: PAULA, João Antônio de (Org.). Presença de Francisco Iglésias. Belo Horizonte: Autêntica, 2001.

ODÁLIA, Nilo. As formas do mesmo: ensaios sobre o pensamento historiográfico de Varnhagen e Oliveira Viana. São Paulo: Editora da UNESP, 1997.

PEREIRA, Mateus H. de F.; SANTOS, Pedro A. C. dos; NICODEMO, Thiago L. Brazilian historical writing in global perspective: on the emergence of the concept of "historiography". History and Theory, Theme Issue 54, december, 2015, p.84-104. 
RANCIÈRE, Jacque. Políticas da escrita. Rio de Janeiro: Editora 34, 1995.

REVEL, Jacques. História e Historiografia: exercício críticos. Curitiba: Editora da UFPR, 2010.

REVISTA DE HISTÓRIA. São Paulo: Universidade de São Paulo, Num. 88, 1971.

RODRIGUES, Lidiane Soares. A produção social do marxismo universitário em São Paulo: mestres, discípulos e 'um seminário'. Tese de doutorado apresentada ao programa de pósgraduação em História Social da Universidade de São Paulo, 2011, p. 565.

ROIZ, Diogo da Silva. Os caminhos (da escrita) da história e os descaminhos de seu ensino: a institucionalização do ensino universitário de História na Faculdade de Filosofia, Ciências e Letras da Universidade de São Paulo (1934-1968). Curitiba: Appris, 2012.

ROIZ, Diogo da Siva; FARIAS, Marcilene Nascimento de. Eduardo de Oliveira França e a escrita da história das civilizações. Revista Emblemas, V.8., N.2., Jul.-Dez., 2011.

SANTOS, Alessandra Soares. A universidade, a história e o historiador: o itinerário intelectual de Francisco Iglésias (1940-1990). Tese de doutorado apresentada ao programa de pósgraduação em história da universidade federal de Minas Gerais, 2013, p.350.

WASSERMAN, Claudia. Identidade nacional: o Brasil para seus intelectuais. Revista Acervos, Vol.19., Num. 1-2., jan/dez, 2006, p. 23-36.

WEHLING, Arno. Historiografia e epistemologia histórica. In: MALERBA, Jurandir (org.). A história escrita: teoria e história da historiografia. São Paulo: Contexto, 2006. 